\title{
THE BEHAVIOUR OF CFRP MATERIAL IN MICRO DRILLING PROCESS TOWARDS THRUST FORCE
}

\author{
N. AB WAHAB ${ }^{1}$, SYAFIQABD LATIFF ${ }^{2}$, H. SASAHARA ${ }^{3}$, R. IZAMSHAH ${ }^{4} \&$ N. SYUHADA NASIR \\ ${ }^{1,2,5}$ Fakulti Teknologi Kejuruteraan Mekanikaldan Pembuatan, Universiti Teknikal Malaysia Melaka, Hang Tuah Jaya, \\ 76100 Durian Tunggal, Melaka, Malaysia \\ ${ }^{4}$ Advanced Manufacturing Center, Universiti Teknikal Malaysia Melaka, Hang Tuah Jaya, 76100 Durian Tunggal,
} Melaka, Malaysia

${ }^{3}$ Department of Mechanical Systems Engineering, Tokyo University of Agriculture and Technology, Japan

This research was focusing on a micro drilling process performance towards thrust force and tool wear. Rapid tool wear in the micromachining industry contributed to the negative impact on process cycle time and manufacturing cost. The tool used was micro drill bit HSS Carbide with diameter $0.9 \mathrm{~mm}$. Carbon Fiber Reinforced Polymer (CFRP) was the material selected for the workpiece of this experiment. The purpose of the study is to select the optimum parameter of micro drilling process towards minimum thrust force as well as the tool wear. This research had been conducted with data collection on the range of the selected cutting parameter. The significant parameter had been defined by Analysis of variance (ANOVA). Taguchi L27 Method was used for screening and eliminating the parameter that was not significant and there was found that the combination of the lowest feed rate of $0.001 \mathrm{~mm} / \mathrm{rev}$ with the spindle speed of 8,000 - 12,000 rpm produced higher thrust force. Thus, this feed rate was eliminated for the optimization stage. Finally, 2-Level Factorial Method has been applied to optimize the parameter of the experiment. It was found that the lowest thrust force was contribute by the combination of spindle speed $8,000 \mathrm{rpm}$ and feed rate $0.01 \mathrm{~mm} / \mathrm{rev}$. As a result, it showed that value of feed rate had significant effect on thrust force during micro drilling process.

KEYWORDS: Micro Drilling; CFRP; Taguchi; Cutting Parameter; Thrust Force
\end{abstract}

Received: Jun 06, 2020; Accepted: Jun 26, 2020; Published: Aug 31, 2020; Paper Id.: IJMPERDJUN2020975

\section{INTRODUCTION}

Micro-drilling is a drilling process that use the drill bit with the diameter below than $1 \mathrm{~mm}$. The optimized size of the micro drill bit is $0.9 \mathrm{~mm}$ shows better effect compare to $0.7 \mathrm{~mm}$ and $0.8 \mathrm{~mm}$ [1]. Micro drilling process provides micro size of holes that improve the accuracy in dimension and shape of the hole. The application of micro holes is usually on the small or miniature components. The example of the miniature components is AFT Anti-Backlash Super nut (AFT), Micro guide, Glide Screw and Micro Stage.

Since the CFRP composite is a material that high tensile strength and abrasion resistance [2], the drilling of this material always facing a major problem especially in rapid tool wear and hole quality. Thrust force during process lead to major impact on tool wear formation and delamination which can be controlled by low feed rate [3]. Too low feed rate will enhance the heating that had been surrounded by the matrix material.

The high cutting speed with the minimum value of torque will cause a negative impact to the strain rate [4]. The variant parameter of cutting speed will produce unpredictable behaviour from the result. The right selection of core drill will reduce delamination by using the high speed of cutting. Drilling stack up to cause by the presence 
of abrasive and tool wear between the contact of composite and metal [5]. It will decrease the tool life and quality of the hole. It will highly cost when there are tool life wear issues in the process.

Friction performance of material defined as the force resisting the relative motion between two sliding interfaces [6]. The instrument that uses for analysing tool wear is an SEM microscope. There is another way to identify cutting forces by using a numerical technique [7]. Tribology properties of the material also studied to understand the relationship between interacting surfaces with the motion between friction, wear and lubrication. Fibre Quality, premise weight and fibre bonding will impact the material properties [8].

\section{METHODOLOGY}

The overall setup of the experiment in CNC Router machine MDX-540 shows in Fig 1. The jig is required to prevent the dynamometer from damage when the drill bit passed through the CFRP composite during the drilling process. The dynamometer will capture the real-time value of force existing during the drilling process. The operation of drilling and measuring force should be simultaneously to gain a specific value. Dynamometer Type 9257BA with tool holder Type 9403 mounted use for measuring the cutting force. Its software is Dyno Ware Type 2825A that provided in the system is purposely for transaction data and display software to measure the cutting force.

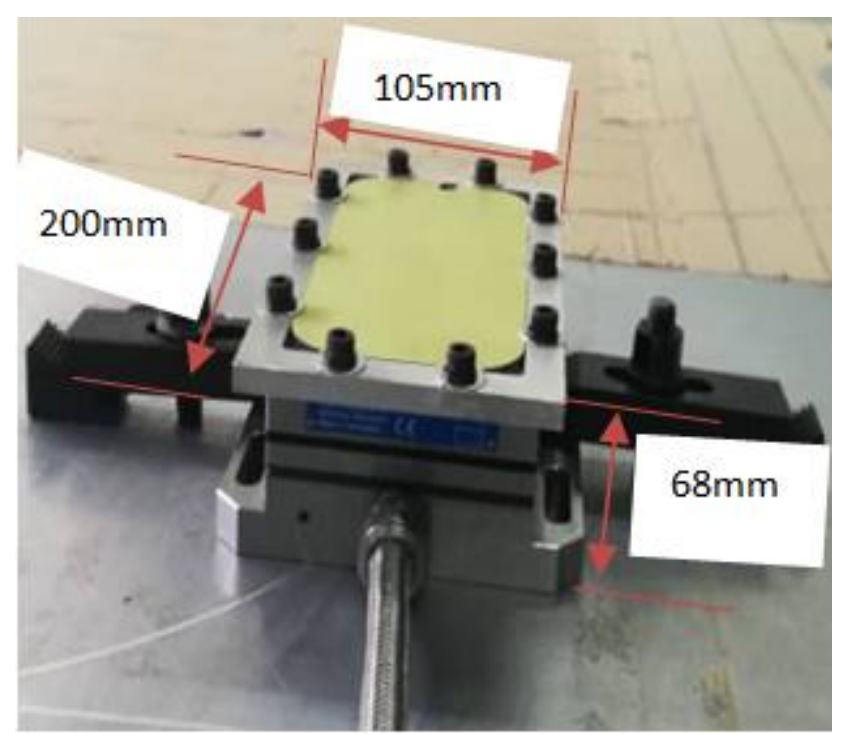

Figure 1: Experiment Setup of Micro-Drilling Process on CFRP Composite.

Fig 2 shows the flow chart of this research to achieve the objective of this research which are characterize the effect of micro-drilling of CFRP and drilling parameters on thrust force. 


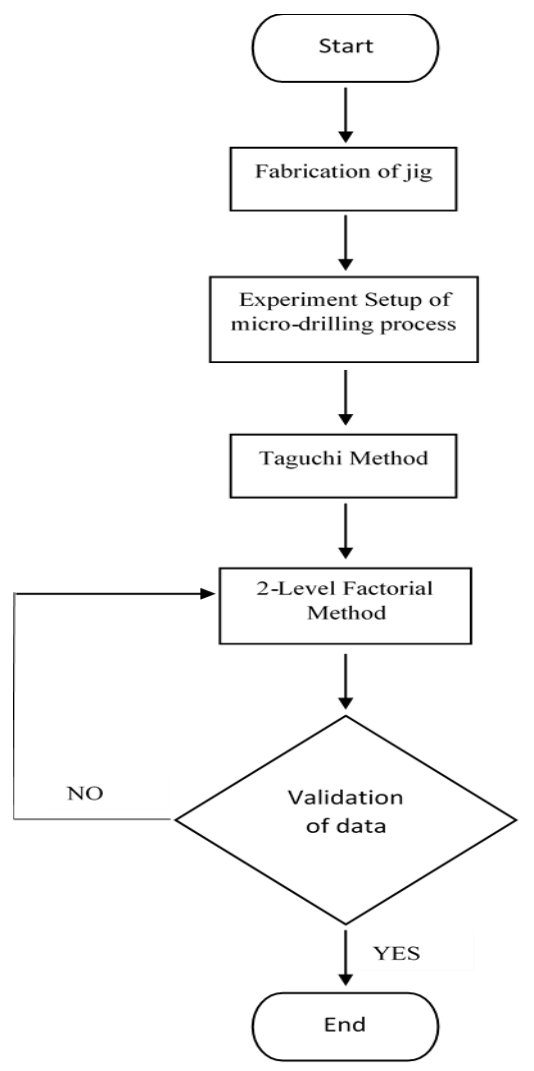

Figure 2: The Flow Chart of the Research.

\section{Design and Fabrication of Jig}

Milling machine, work-piece, fixture and cutter is needed for milling process [9]. The designation and fabrication are jigs that attach between composite and dynamometer had been applied. Clamping in processing normally use instruments and holding device such as a vise to brace workpiece [10]. CATIA V5 R20 was selected because it is useful to ComputerAided Design (CAD) and Computer-Aided and Manufacturing (CAM). The material of the jigs is aluminium. Size of the part is $200 \mathrm{~mm} \times 105 \mathrm{~mm} \times 8 \mathrm{~mm}$. The process that involves in CAM shows in Table 1 .

Table 1: The Features of Machining jig in CAM

\begin{tabular}{|c|c|c|c|}
\hline No. & $\begin{array}{c}\text { Name of } \\
\text { process }\end{array}$ & Description & $\begin{array}{c}\text { This process cut material in flat } \\
\text { movement to reduce the thicness, } \\
\text { length or width. This features used } \\
\text { face mill diameter 63 mm. }\end{array}$ \\
\hline 1 & Facing & $\begin{array}{c}\text { It cut the material on the target } \\
\text { region without reach any regain that } \\
\text { need to remain. It will create edge } \\
\text { between two flat surface. This } \\
\text { feature used end mill with diameter } \\
\text { 20mm 8mm and 6mm. }\end{array}$ \\
\hline 3 & Prilling & $\begin{array}{c}\text { This process use drill bit to create a } \\
\text { hole by drilling. This feature used } \\
\text { drill bit with diameter 5mm and 8 } \\
\text { mm. }\end{array}$ \\
\hline 4 & Tapping & $\begin{array}{c}\text { It will create internal thread in the } \\
\text { hole. This feature used Tap M6. }\end{array}$ \\
\hline
\end{tabular}




\section{Tribology Testing of CFRP Composite}

Tribology is the study of interacting surfaces in relates motion between friction, wear and lubrication. Coefficient friction is equal to friction force per normal force. The machine that had been used to carry out this experiment is Micro POD Tribology Tester which capable to control by software shows in Figure 3.9. The software used to command is Winducom 2010. The process parameter of the experiment for this testing shows in Table 2. The purpose of this test is identifying the coefficient friction.

Table 2: The Parameter of Tribology Test

\begin{tabular}{|c|l|c|c|}
\hline No. & Parameter & Value & Unit \\
\hline 1 & Set Stroke & 1 & $\mathrm{~mm}$ \\
\hline 2 & Duration & 30 & $\mathrm{~min}$ \\
\hline 3 & Set Velocity & 20 & $\mathrm{~mm} / \mathrm{sec}$ \\
\hline 4 & Load & $5,10,15$ & $\mathrm{~N}$ \\
\hline
\end{tabular}

\section{Design of Experiment}

Taguchi method is experimental design by using an orthogonal array that reduces the number of experiments. Signal to noise ratio $(\mathrm{S} / \mathrm{N})$ is a type of variance analysis suggested by this method. This experiment had set "smaller-is-better" to identify the lowest thrust force and minimize the loss of quality data. Response table and the main effect for the analysis gain from Minitab 17 Software. Table 3 shows the list of the experiment from 3 levels of the parameter. This DOE had been repeated for three times to gain the average of thrust force for every single experiment.

Table 3: Experimental Design by Taguchi Method

\begin{tabular}{|c|c|c|c|}
\hline \multirow{2}{*}{ No. } & \multicolumn{3}{|c|}{ Parameter } \\
\cline { 2 - 4 } & Spindle Speed (rpm) & Feed rate $(\mathbf{m m} / \mathbf{r e v})$ & Feed rate $(\mathbf{m m} / \mathbf{m i n})$ \\
\hline 1 & 8000 & 0.001 & 8 \\
\hline 2 & 8000 & 0.01 & 80 \\
\hline 3 & 8000 & 0.015 & 120 \\
\hline 4 & 10000 & 0.001 & 10 \\
\hline 5 & 10000 & 0.01 & 100 \\
\hline 6 & 10000 & 0.015 & 150 \\
\hline 7 & 12000 & 0.001 & 120 \\
\hline 8 & 12000 & 0.01 & 180 \\
\hline 9 & 12000 & 0.015 & \\
\hline
\end{tabular}

Next, the experiment would be further by design 2-Level Factorial shows in Table 4. It is important to optimize the lowest thrust force for micro-drilling process on CFRP composite. The result from Taguchi L27 will identify the input that would be eliminated due to the lowest thrust force produced during the process. The main objective of this research is to identify the lowest thrust force that will solve many problems in manufacturing especially issues on hole accuracy and tool wear. 
Table 4: Experimental Design by 2-Level Factorial

\begin{tabular}{|c|c|c|c|}
\hline \multirow{2}{*}{ Run } & \multicolumn{3}{|c|}{ Parameter } \\
\cline { 2 - 4 } & Spindle speed (rpm) & Feed rate (mm/rev) & Feed rate (mm/min) \\
\hline 1 & 10000 & 0.0125 & 125 \\
\hline 2 & 8000 & 0.01 & 80 \\
\hline 3 & 10000 & 0.0125 & 125 \\
\hline 4 & 10000 & 0.0125 & 125 \\
\hline 5 & 12000 & 0.015 & 180 \\
\hline 6 & 10000 & 0.0125 & 125 \\
\hline 7 & 10000 & 0.0125 & 125 \\
\hline 8 & 8000 & 0.015 & 120 \\
\hline 9 & 12000 & 0.01 & 120 \\
\hline
\end{tabular}

The experiment continues by CNC Router Machine model MDX-540. This machine has higher performance in spindle speed which is maximum spindle speed on $12000 \mathrm{rpm}$. CAD software which Solid work used to mark every hole on the experiment. This distance is important to ensure the micro drill bit will not touch to the jigs. It had been shown in Fig 3.

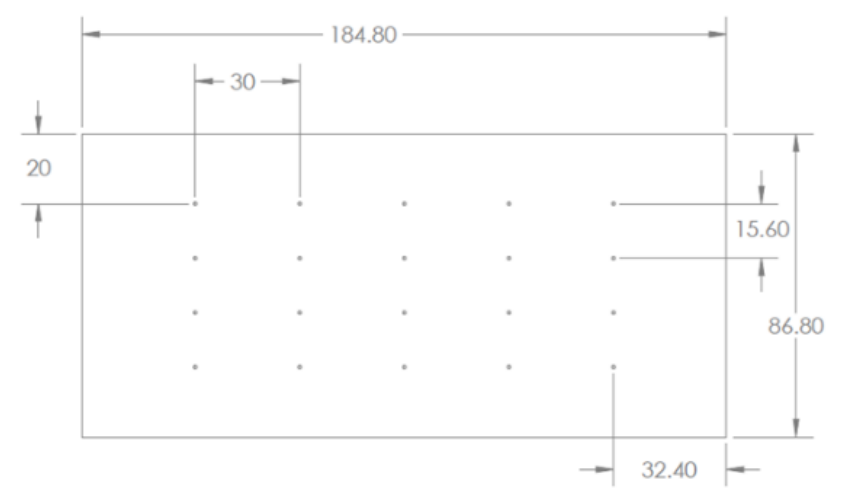

Figure 3: The Dimension of Drilling Point.

\section{Evaluation Method of Thrust Force}

Dyno ware software will process the data of micro-drilling into thrust force shows in Fig 4. The main concern in the evaluation of data is a region of interest. It is the region where the drill bit is going to drill or cut the CFRP composite. The region that other than the region of interest is the region that drill bit travel from one hole to another hole until the experiment end.

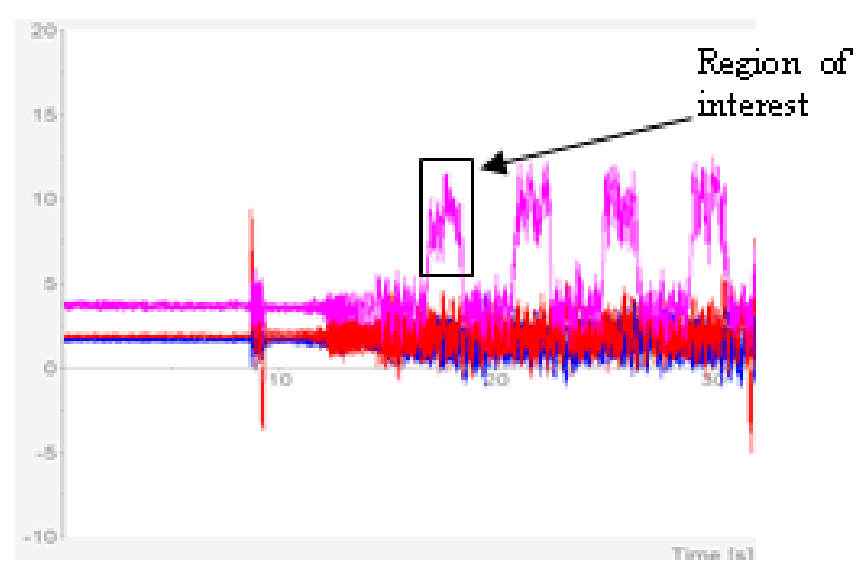

Figure 4: The Graph of Thrust Force Produced by Dyno Ware Software. 


\section{Observation Method of Tool Wear}

Generally, tool wear can be observed by Scanning Electron Microscope (SEM) that apply on the micro drill bit. It consists of an electron optical system that produces an electron probe to scan the surface of the specimen. The application of this machine in the industry had been developed for the sophisticated instrument. The drill bit place in SEM workplace shows in Fig 5 .

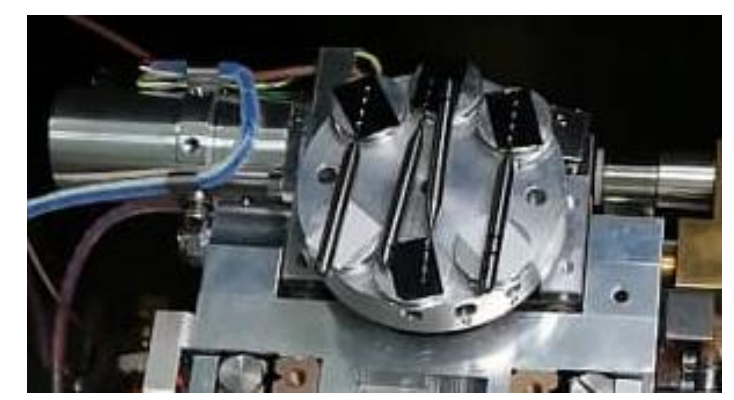

Figure 5: Image of Specimen Place in SEM.

It observed the surface of a specimen by using the light radiation of the electron beam. Fig 6 shows the image of the tool wear under SEM observation. This image was zoom into 80x Magnificent.

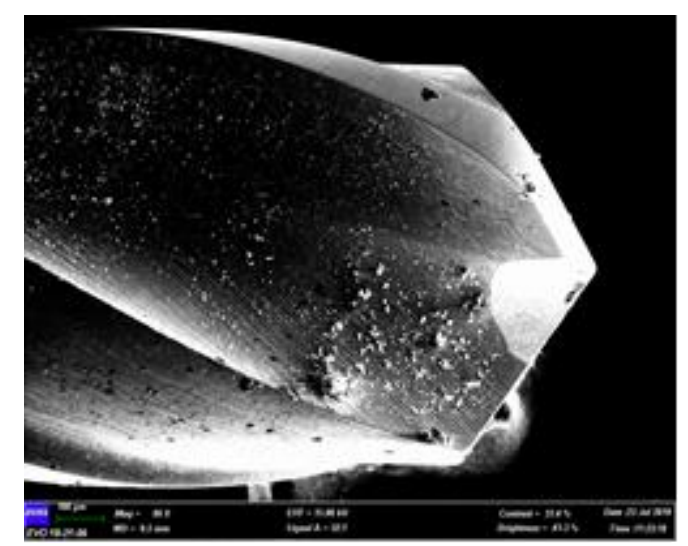

Figure 6: The Image of Tool Wear Captured by SEM.

\section{RESULTS AND DISCUSSION}

\section{The Behaviour of Tribological on CFRP Panel}

Tribology test was carried on CFRP composite by using ball on disk machine with various load, which is $5 \mathrm{~N}, 10 \mathrm{~N}$ and $15 \mathrm{~N}$. The data of coefficient friction, wear rate and surface roughness had been collected shows in Table 5 .

Table 5: The Result of Tribology Test

\begin{tabular}{|c|c|c|c|}
\hline Load (N) & Average Coefficient Friction & Average Surface Roughness, Ra (um) & $\begin{array}{c}\text { Average Surface } \\
\text { Roughness, Rz (um) }\end{array}$ \\
\hline 5 & 0.0244 & 0.50 & 3.06 \\
\hline 10 & 0.1634 & 0.68 & 3.60 \\
\hline 15 & 0.1782 & 0.98 & 4.40 \\
\hline
\end{tabular}

The result shows that the higher the load apply on the ball of the tribology test will produce higher friction force and normal force. The coefficient friction is the value of friction force per normal force. The higher the coefficient friction will produce a higher value of surface roughness. 


\section{Result of Experiment by Taguchi Method}

The design of experiment Taguchi method L27 produce nine runs of the experiment. The code of E, F and G represented three times of run in the same input parameter to evaluate the output specifically shows in Table 6. All data will sum and divide into three to gain the average data for every nine parameters that had been set.

Table 6: The Data of Thrust Force by Taguchi Method L9

\begin{tabular}{|c|c|c|c|c|}
\hline \multirow{2}{*}{ No. } & \multicolumn{3}{|c|}{ Thrust Force (N) } & \multirow{2}{*}{ Average Thrust Force (N) } \\
\cline { 2 - 4 } & $\mathbf{E}\left(\mathbf{1}^{\text {st }}\right.$ run $)$ & $\mathbf{F}\left(\mathbf{2}^{\text {nd }}\right.$ run $)$ & $\mathbf{G ~}^{\text {rd }}$ run $)$ & \\
\hline 1 & 8.3145 & 8.6690 & 8.0449 & 8.3428 \\
\hline 2 & 5.1289 & 5.0773 & 5.1014 & 5.1025 \\
\hline 3 & 5.1916 & 5.1380 & 6.8238 & 5.7178 \\
\hline 4 & 7.7737 & 8.3560 & 6.6236 & 7.5844 \\
\hline 5 & 5.4118 & 5.1631 & 5.9525 & 5.5091 \\
\hline 6 & 6.0583 & 5.0746 & 6.0449 & 5.7259 \\
\hline 7 & 7.5302 & 7.7423 & 6.2237 & 7.1654 \\
\hline 8 & 4.8148 & 5.4551 & 5.9754 & 5.4151 \\
\hline 9 & 4.6706 & 4.8906 & 5.7957 & 5.1189 \\
\hline
\end{tabular}

$\mathrm{S} / \mathrm{N}$ ratio graph will compare the level of the desired signal to the response affected by the factors. Fig 7 shows the ranking between every level parameter. The highest rank of spindle speed is $12000 \mathrm{rpm}$ and feed rate $0.01 \mathrm{~mm} / \mathrm{rev}$.

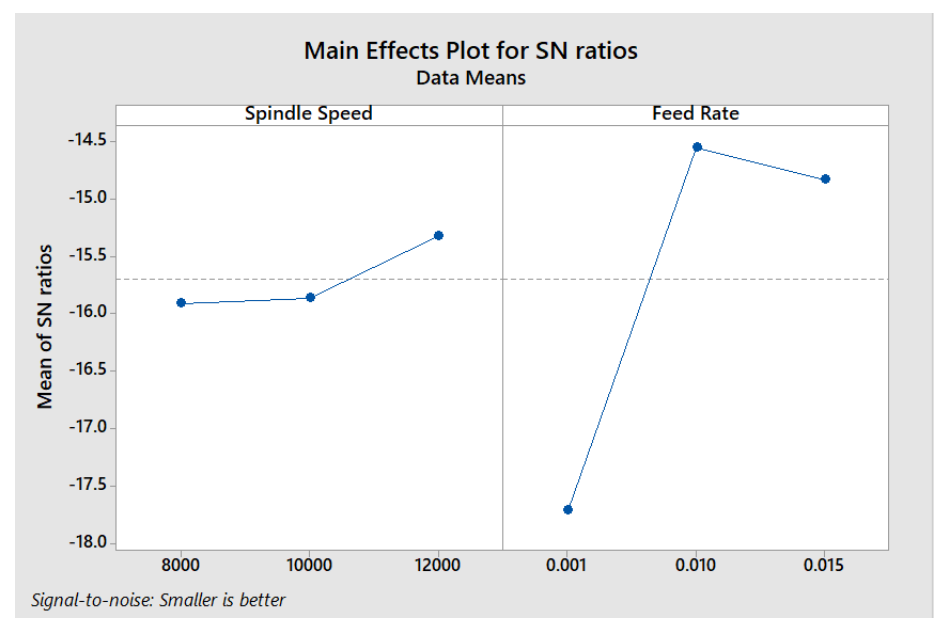

Figure 7: S/N Ratio Graph of Thrust Force Experiment.

The degree of slope is smalls between three level of spindle speed produce thrust force due to spindle speed is less affecting to gain the lowest thrust force. The right plot shows that feed rate $0.001 \mathrm{~mm} / \mathrm{rev}$ is produced highest thrust force. The degree of slope between $0.001 \mathrm{~mm} / \mathrm{rev}$ and $0.01 \mathrm{~mm} / \mathrm{rev}$ is higher than the degree of slope between $0.01 \mathrm{~mm} / \mathrm{rev}$ and $0.015 \mathrm{~mm} / \mathrm{rev}$. Therefore, it is relevant to eliminate the feed rate of $0.001 \mathrm{~mm} / \mathrm{rev}$ because it is the most affecting parameter to identify the lowest thrust force.

\section{Result of Experiment by 2-Level Factorial}

The result from Taguchi L27 eliminated the most influential factor that will create a high trust force that will interrupt the main objective of this research. This experiment had been designed with two factors with two level of each factor and the centre point per block is five shows in Table 7. This selection with increase the accuracy of the experiment data compares to three centre point per block. Centre point per block is the number of repeated experiments in the centre of the design. 
Table 7: The Result of Thrust Force for 2-Level Factorial

\begin{tabular}{|c|c|c|c|}
\hline Run & Spindle Speed (rpm) & Feed Rate (mm/rev) & Thrust Force(N) \\
\hline 1 & 10000 & 0.0125 & 5.6267 \\
\hline 2 & 8000 & 0.01 & 6.4888 \\
\hline 3 & 10000 & 0.0125 & 7.016 \\
\hline 4 & 10000 & 0.0125 & 6.6894 \\
\hline 5 & 12000 & 0.015 & 6.8275 \\
\hline 6 & 10000 & 0.0125 & 6.9092 \\
\hline 7 & 10000 & 0.0125 & 6.3742 \\
\hline 8 & 8000 & 0.015 & 9.6486 \\
\hline 9 & 12000 & 0.01 & 8.1855 \\
\hline
\end{tabular}

The result of the experiment had been analysed by using Analysis of Variance (ANOVA) shows in Fig 8 . The model with prob $>\mathrm{F}$ is 0.049046 shows it is less than 0.05 . Therefore, the model of the experiment is significant to optimize the lowest thrust force.

\begin{tabular}{|c|c|c|c|c|c|c|}
\hline \multicolumn{7}{|c|}{$\begin{array}{l}\text { Response: Thrust Force } \\
\text { ANOVA for Selected Factorial Model }\end{array}$} \\
\hline \multicolumn{7}{|c|}{ Analysis of variance table [Partial sum of squares] } \\
\hline & Sum of & & Mean & $\mathbf{F}$ & & \\
\hline Source & Squares & DF & Square & Value & Prob $>\mathrm{F}$ & \\
\hline \multirow[t]{4}{*}{ Model } & 6.2303 & 3 & 2.0768 & 6.6706 & 0.049046 & significant \\
\hline & 0.31608 & 1 & 0.31608 & 1.0153 & 0.37065 & \\
\hline & 0.81164 & 1 & 0.81164 & 2.6070 & 0.18169 & \\
\hline & 5.1026 & 1 & 5.1026 & 16.390 & 0.015496 & \\
\hline Curvature & 3.5534 & 1 & 3.5534 & 11.414 & 0.027826 & significant \\
\hline Pure Error & 1.2453 & 4 & 0.31133 & & & \\
\hline Cor Total & 11.029 & 8 & & & & \\
\hline
\end{tabular}

Figure 8: The Analysis of Variance Produced by Design-Expert Software.

There is only a $2.78 \%$ chance that a "Curvature F-value" this large could occur due to noise. The value of standard deviation is 0.55797 and R-square is 0.83342 . The signal to noise ratio is greater than 4 is desirable where this experiment is 7.598. The hypothesis of the experiment can be described on the 3D surface model shown in Fig 9. Low spindle speed on $8000 \mathrm{rpm}$ and high feed rate of $0.015 \mathrm{~mm} / \mathrm{rev}$ will produce highest thrust force at $9.6486 \mathrm{~N}$. The lowest thrust force with value $6.489 \mathrm{~N}$ can be identified on factors of spindle speed at $8000 \mathrm{rpm}$ and feed rate $0.01 \mathrm{~mm} / \mathrm{rev}$.

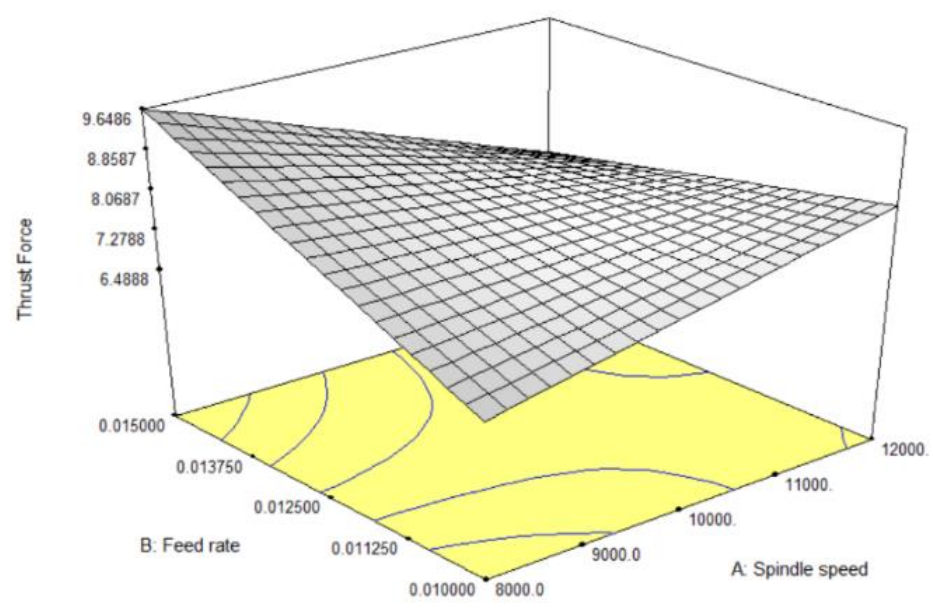

Figure 9: 3D Surface Model of 2-Level Factorial Result. 
Next, the validation is required to ensure the accuracy of the optimization on the lowest thrust force of microdrilling experiment. The final run of the experiment had been done to identify the percentage of the difference between target data and the actual data shown in Table 8. Design expert software had predicted the value of thrust force that produce during validation. All of the experiment setup and standard of operational procedure had been following to gain the accurate result on the final run experiment.

Table 8: The Detail of Validation Experiment
\begin{tabular}{|l|c|}
\hline Factors / Condition of Experiment & Value \\
\hline Spindle speed (rpm) & 8000 \\
\hline Feed rate (mm/rev) & 0.01 \\
\hline Diameter of drill bit (mm) & 0.9 \\
\hline No. of hole & 20 \\
\hline Target thrust force (N) & 6.4888 \\
\hline Actual thrust force (N) & 6.86 \\
\hline Percentage of difference (\%) & 5.7 \\
\hline
\end{tabular}

The difference between actual and target result had been calculated to identify the validation is accept or not. The value of acceptance is $5-10 \%$. The difference between both data is $5.7 \%$ which the actual results produce more than the target result. Therefore, the validation of the optimization thrust force on 2-level factorial is acceptable.

\section{CONCLUSIONS}

For this research, all the objectives achieved since the optimize parameter of the lowest thrust force had been identified. The jig had successfully designed and fabricated to perform the process of micro-drilling to measure the thrust force. Taguchi Method L27 had been used for eliminating the range of parameter that will produce high trust force during the micro-drilling process on CFRP panel. Five centre blocks represent five times of experiment had been done to increase the effectiveness of parameter. The optimize parameter of micro-drilling process on CFRP panel is spindle speed $8000 \mathrm{rpm}$ and feed rate $0.01 \mathrm{~mm} / \mathrm{rev}$. This research proves that the set of value for spindle speed in the range $8000 \mathrm{rpm}-12000 \mathrm{rpm}$ is not affecting on lowest thrust force but the lower the feed rate will give high impact to identify the lowest thrust force. Besides, the properties of wear rate and friction force had been identified by using the tribological test to understand the material properties of CFRP composite that had been used in this research.

\section{ACKNOWLEDGEMENTS}

This work is partially supported by Universiti Teknikal Malaysia Melaka (UTeM) and the Malaysia Ministry of Higher Education for the financial funding under Grant No. FRGS/2018/FTKMP-AMC/F00387.

\section{REFERENCES}

1. K. Shunmugesh and K. Panneerselvam, "Optimization of process parameters in micro-drilling of Carbon Fiber Reinforced Polymer (CFRP) using taguchi and grey relational analysis," Polym. Polym. Compos., 2016.

2. E. D. Eneyew and M. Ramulu, "Experimental study of surface quality and damage when drilling unidirectional CFRP composites, "J. Mater. Res. Technol., 2014.

3. Ravichandran, M., et al. "Design And Analysis of Connecting Rod By Using CFRP Material." Research and Development (IJAUERD) 3.2 (2013): 81-88.

4. R. Melentiev, P. C. Priarone, M. Robiglio, and L. Settineri, "Effects of Tool Geometry and Process Parameters on Delamination in CFRP Drilling: An Overview, " in Procedia CIRP, 2016. 
5. J. L. Merino-Pérez, R. Royer, E. Merson, A. Lockwood, S. Ayvar-Soberanis, and M. B. Marshall, "Influence of workpiece constituents and cutting speed on the cutting forces developed in the conventional drilling of CFRP composites," Compos. Struct., 2016.

6. A. S. Ma. Hassan, M H, J Abdullah, "MH Hassan et. el, 2018, Effect of drill geometry and drilling parameters on the formation of adhesion layer in drilling compositemetal stack- up material.pdf." pp. 90-98, 2018.

7. Suman, Swapnil, et al. "Experimental investigation on influence of functionalized multi-walled carbon nanotubes on surface roughness in drilling of cfrp composites." International Journal of Mechanical and Production Engineering Research and Development (IJMPERD 8.3 (2018): 1133-1146.

8. U. Nirmal, J. Hashim, and S. T. W. Lau, "Testing methods in tribology of polymeric composites," Int. J. Mech. Mater. Eng., 2011 .

9. N. Wahab and H. Sasahara, "Identification of Friction Characteristics and Flow Stress of 0.45\% Carbon Steel during Cutting Process, " Adv. Mater. Res., 2015.

10. N. B. A. Wahab, A. Arafah, Y. Fukuzawa, and S. Nagasawa, "Estimation of corrugated cardboard strength using tensile test," Proc. Mech. Eng. Res. Day 2016, no. March, pp. 110-111, 2016.

11. Al-Tameemi, Mohammed Dheyaa, and R K Pandey. "Experimental Study on The Behavior of RC T Beams Strengthened with Externally Bonded CFRP." Research and Development (IJCSEIERD) 3.4 (2013): 73-80.

12. N. B. A. Wahab, "Development of fixable rotation clamping method for milling machine," no. May, pp. 109-110, 2017.

13. N. A. Wahab et al., "Design Optimization and Development of Portable Vacuum Clamping ( VacCLAMP ) Based on Machining Performances," no. 01, 2018. 